\title{
Number of Characters Read
}

National Cancer Institute

\section{Source}

National Cancer Institute. Number of Characters Read. NCI Thesaurus. Code C142353.

The number of letters read by the subject during an eye chart assessment. 